\title{
Isolation, Screening and Characterization of Phosphate Solubilizing Bacteria from Karwar Costal Region.
}

\author{
Sanjotha $G^{*}$ \& Sudheer Manawadi \\ Department of Biotechnology, Government arts and Science Sollege Karwar. Karnataka, India. \\ guruvinsc@gmail.com
}

\begin{abstract}
Phosphorus solubilizing bacteria (PSB) play important role by enhancing its availability to plants through release from inorganic and organic soil $P$ by solubilization and mineralization. Phosphorus is vital to seed formation and its content is higher in seeds than in any other part of the plant. It helps plants to survive winter seasons and also contributes to disease resistance in some plants. Also known to improve quality of many fruits, vegetables and grain crops. The ability of some microorganisms to convert insoluble phosphorus to a soluble form, like orthophosphate, is an important trait in a Plant growth promoting bacteria for increasing plant yields. The inoculation of P-solubilizing microorganisms (PSM) is an efficient technique because it can increase $P$ availability in the soil. In the present work we have made efforts to isolate the phosphate solubilizing microorganism form soil followed by its biochemical characterization. In this study, isolation, screening and characterization of 35 isolates of phosphate solubilizing bacteria from different regions of karwar were carried out. Phosphate solubilizing activities of all isolates were tested on National Botanical Research Institute's phosphate growth medium (NBRIP), and Pikovskaya medium (PVK), medium by analyzing the soluble-P content with different incubation temperature and $p H$. This article incorporates the recent developments and Preliminary results obtained in the manipulation of bacterial strains for improving capacity for phosphate solubilization and application of this knowledge to improving agricultural inoculants is discussed.
\end{abstract}

Keywords: phosphate solubilizing bacteria, Phosphate Solubilization Efficiency, phosphate, NBRIP and PVK media

\section{INTRODUCTION}

Phosphorus is one of the most essential major growth-limiting plant nutrient which affect the overall growth of plants [1] by influencing various key metabolic processes such as cell division and development, macromolecular biosynthesis, photosynthesis and respiration of plants $[2,3,4,5,6]$. The maximum part of soil phosphorous, approximately $95-99 \%$ is present in the form of insoluble phosphates and hence it cannot be easily utilized by the plants [7]. Phosphorus plays an important biochemical role energy storage and transfer, cell enlargement and several other processes in the living plant. Insoluble phosphate compounds can be solubilized by organic acids and phosphatase enzymes produced by plants and microorganisms. Insoluble phosphorous is solubilized by a major group of soil microflora was reported and these complexes enabling plants to easily absorb phosphorous. Several reports have examined the ability of different bacterial species to solubilize insoluble inorganic phosphate compounds, such as tricalcium phosphate, dicalcium phosphate, hydroxyapatite, and rock phosphate. Among the bacterial genera with this capacity are Pseudomonas, Bacillus, Rhizobium, Burkholderia, Achromobacter, Agrobacterium, Microccocus, Aereobacter, Flavobacterium and Erwinia.

In comparison to other nutrients like $\mathrm{N}, \mathrm{P}$ concentration in soil solution is very low and ranges from 0.001 to $1 \mathrm{mg} / 1$ [8]. The low level of phosphorous is due to high reactivity of soluble phosphate with other elements. In soil, P compounds are placed into three categories: (i) inorganic compounds, (ii) organic compounds of the soil humus and (iii) organic and inorganic $\mathrm{P}$ compounds associated with the cells of living matter. The microbial world can derive out huge amount of nutrient from the natural source and enrich the soil with important but scarce nutrients. The organisms with phosphate solubilizing potential increase the availability of soluble phosphates and can enhancing the availability of trace elements such as iron, zinc etc.by increasing the plant growth efficiency of biological nitrogen fixation. Many Rhizobacteria are able to solubilize soluble phosphates, by 
releasing chelating organic acids [9]. Inoculation of phosphate solubilizing bacteria like Pseudomonas and Bacillus species on wheat (Triticum aestivum L.) resulted in increase in grain yield and phosphorous uptake [10]. Field experiments revealed that P -solubilizing bacteria (PSB) not only improved the quality and growth of plants but also drastically reduced (1/3-1/2) the usage of chemical organic fertilizers. Crop plants such as peanut, various horticultural plants, and vegetables were successfully inoculated with PSB to obtain higher yields. The performance of PSB is severely influenced by environmental factors especially under stress conditions. The objective of this study was to isolate, identify and characterize Phosphate solubilizing microorganisms from the coastal area of karwar Uttara Kannada, Karnataka.

\section{Materials AND Methods}

\subsection{Collection of Sample}

The soil samples were collected randomly from depth of 5-17 $\mathrm{cm}$ from the different regions of karwar costal area, Karnataka. All collected soil samples were stored in polythene bags and transported to laboratory aseptically and maintained and stored at $4^{\circ} \mathrm{C}$ prior to be analyzed. These samples were airdried and ground to pass through $2 \mathrm{~mm}$ sieve before the microbial analysis.

\subsection{Isolation of Microbes}

Isolation of Phosphate solubilizing bacteria was performed by suspending $1 \mathrm{~g}$ rhizosphere soil in $100 \mathrm{ml}$ of distilled water. An aliquot (100 micro lit) from decimal dilutions was inoculated on National Botanical Research Institute's phosphate growth medium (NBRIP) [11], and Pikovskaya medium (PVK) [12], by pour plate technique and incubated at $31^{\circ} \mathrm{C}$. The $\mathrm{pH}$ of the media was adjusted to 7.0 before autoclaving. Colonies showing phosphate solubilizing zone around them were considered as PSM. Single colonies appearing on Picovskaya agar plates were transferred in liquid broth of Picovskaya and on agar slants for further study.

\subsection{Identification and Charecterization of Microbes}

The fungi identification was performed by a drop of lacto phenol cotton blue placed on glass slide and observed under microscope. The bacteria was identified by morphological characteristic in which different shapes, staining methods like gram staining and various biochemical testes like IMViC test and motility test including catalase, oxidase test, sucrose, lactose fermentation, starch hydrolysis, Gelatin hydrolysis and Nitrate reduction [13]. To analyze and identify phosphate solubilizing activity a large halo zone producing strains were selected for further study. The halo zone and colony diameters were measured after 15 days of the incubation of plates at $30^{\circ} \mathrm{C}$. Colonies of PSB were detected by clear zones of solubilization around them. The isolates were identified following Bergey's manual for bacteriology methods systematic.

The analysis of phosphate solubilizing activity of the selected isolates were conducted qualitatively and quantitatively by plate screening method and broth culture method.

\subsection{Qualitative Screening of Psm}

An efficient protocol was developed for qualitative screening of phosphate-solubilizing bacteria, based upon visual observation. Our results indicate that, by using bromophenol blue, it is possible to quickly screen on a qualitative basis the phosphate-solubilizing bacteria. Qualitative estimation of all the suspected phosphate solubilizing bacteria were screened by inoculating and growing On PVK medium and NBRIP medium with bromophenol blue. PSM were incubated at $38^{\circ} \mathrm{C}$. Diameter of halo zone was measured after 42 hours, up to 15 days. The Phosphate Solubilization Efficiency (PSE) was identified by measuring the total halo zone of the colony and the colony diameter [14].

$$
\mathrm{PSE}=\frac{\text { Colony diameter }+ \text { Halo zone diameter }}{\text { Colony diameter }}
$$

\subsection{Quantitative Screening of Psm}

Determination of available phosphorous was performed by using Phospho molybdate blue color method. PVK and NBRIP broth (100ml) (adjusted to PH 7) with Tricalcium phosphate $(0.4 \mathrm{~g} / 100 \mathrm{ml})$ was poured in $250 \mathrm{ml}$ flasks. The flasks were autoclaved at $121^{\circ} \mathrm{C}$ for 20 minutes. In each autoclaved flask, $1 \mathrm{ml}$ of each phosphate solubilizing bacterial strains were inoculated and placed on rotary shaker 
at $10000 \mathrm{rpm}$ for 11 days. The suspension was centrifuged (10000 rpm, for $15 \mathrm{~min})$ to remove bacterial cells and other insoluble materials. The available phosphorous $(\mathrm{P})$ was determined using spectrophotometer at $882 \mathrm{~nm}$ and calibrated with standard $\mathrm{KH}_{2} \mathrm{PO}_{4}$ curve.

\subsection{Optimization of Temperature and $\mathrm{pH}$}

The effect of temperature and $\mathrm{pH}$ on phosphate solubilizing ability of the microbes was studied on Pikovskaya agar and ( $\mathrm{pH} 7.0)$ and NBRIP agar with incubation temperature $27^{\circ} \mathrm{C}, 32^{\circ} \mathrm{C}, 37^{\circ} \mathrm{C}, 42^{\circ} \mathrm{C}$ and $47^{\circ} \mathrm{C}$ and Pikovskaya agar adjusted at different $\mathrm{pH}$ values 5.5, 6.5, 7.5, 8.5, and 9.5, with incubation temperature $30^{\circ} \mathrm{C}$.

\section{RESULTS AND DISCUSSION}

Totally, 35 isolates were obtained from 15 soil samples and the samples were screened for phosphate solubilization ability, of these 5 microbial isolates showed highest Phosphate Solubilization Index (PSI) ranged from $2.0-2.63$ on both PVK and NBRIK media were selected for further studies. The microbial colonies showing clear halo zones around the microbial growth were considered as phosphate solubilization were shown in photo no 1 .

The bacterial isolates were further characterized and screened by a series of biochemical reaction and identified as Pseudomonas sp, Rhizobium. Bacillus sp, Azotobacter sp. The morphological and biochemical characteristics of these isolates were shown in the Table 1 and Table 2. From the data tabulated the bacterial isolates Pseudomonas sp, Bacillus sp, and Rhizobium showed high phosphate solubilization activity. From the results it also indicates that the most efficient phosphate solubilizing bacteria can be screened using NBRIP broth assay.

From the result analysis it indicates that phosphate solubilizing activity of the bacterial isolates showed larger halo zone producing and were selected for further study. By conducting plate screening method and broth culture method the phosphate solubilizing activity of the selected bacterial isolates were analyzed by both qualitatively as well as quantitatively. Out of 35 microbial isolates 5 isolates showed highest Phosphate Solubilization Index among these 5 isolates 4 strains in NBRIP agar plates. The PSI measurement was shown in the table 3.

Various physiological conditions were evaluated on phosphate solubilization efficiency of these isolates using various parameters such as $\mathrm{pH}(5.5-9.5)$ and temperature $\left(27^{0} \mathrm{C}-47^{\circ} \mathrm{C}\right)$ the results were shown in table 4 and table 5. The $\mathrm{pH}$ change were well documented by reference [15]. Result analysis showed that quantitative estimation of 4 species in PVK and NBRIP media with Tricalcium phosphate (0.4g/100ml) (Pseudomonas sp.), (Bacillus sp.) (Rhizobium sp.) and (Azatobacter sp) showed highest percent of $\mathrm{P}$ solubilization. They were showed in the table 6 . The phosphate solubilization of all potent strain were optimized for temperature $\left(30^{\circ} \mathrm{C}-45^{\circ} \mathrm{C}\right)$, in which growth seen in between $35^{\circ} \mathrm{C}$ and $40^{\circ} \mathrm{C}$ in which our findings were similar to reference [16-20].

Table 1. Morphological characteristics of the isolates

\begin{tabular}{|l|l|l|l|l|l|l|}
\hline Sl. no & Charecteristics & $\begin{array}{l}\text { PSB1 } \\
\text { A* }\end{array}$ & $\begin{array}{l}\text { PSB2 } \\
\text { R* }\end{array}$ & $\begin{array}{l}\text { PSB3 } \\
\text { B* }\end{array}$ & $\begin{array}{l}\text { PSB4 } \\
\text { P* }\end{array}$ & $\begin{array}{l}\text { PSB5 } \\
\text { B* }\end{array}$ \\
\hline $\mathbf{1}$ & Gram staining & G-ve & G-ve & G+ve & G-ve & G+ve \\
\hline $\mathbf{2}$ & Shape & Rods & Rods & Rods & Rods & Rods \\
\hline
\end{tabular}

Table 2. Biochemical characteristics of the isolates

\begin{tabular}{|c|c|c|c|c|c|c|}
\hline SI. no & Charecteristics & $\begin{array}{l}\text { PSB1 } \\
\text { A* }^{*}\end{array}$ & $\begin{array}{l}\text { PSB2 } \\
\text { R}^{*}\end{array}$ & $\begin{array}{l}\text { PSB3 } \\
\text { B }^{*}\end{array}$ & $\begin{array}{l}\text { PSB4 } \\
\text { P* }^{*}\end{array}$ & $\begin{array}{l}\text { PSB5 } \\
\text { B* }\end{array}$ \\
\hline $\mathbf{1}$ & Methyl red & + & + & - & - & - \\
\hline 2 & Vogues Proskauer & + & + & + & - & + \\
\hline 3 & Starch hydrolysis & + & + & + & + & + \\
\hline 4 & Gelatin Hydrolysis & - & - & + & - & + \\
\hline 5 & H2S production & - & + & - & + & - \\
\hline 6 & Sucrose fermentation & + & + & + & + & + \\
\hline 7 & Indole & + & + & - & - & - \\
\hline 8 & Citrate utilization & + & - & + & + & + \\
\hline 9 & Nitrate reduction & + & + & + & + & + \\
\hline 10 & Lactose fermentation & + & + & + & - & + \\
\hline
\end{tabular}

A=Azotobacter $\mathrm{R}=$ Rhizobium , $\mathrm{B}=$ Bacillus, $\mathrm{P}=$ Pseudomonas

International Journal of Research Studies in Microbiology and Biotechnology (IJRSMB)

Page $\mid 3$ 
Sanjotha G \& Sudheer Manawadi

Table 3. Phosphate Solubilizing Activities of 5 microbes.

\begin{tabular}{|l|l|l|l|l|}
\hline Sl.no & PSB & Zone measurement $(\mathbf{c m})$ & Colony measurment $(\mathbf{c m})$ & $\begin{array}{l}\text { Solubilization } \\
\text { Index(SI)* }\end{array}$ \\
\hline 1 & Azotobacter $s p$ & 1.5 & 1.4 & 2.07 \\
\hline 2 & Rhizobium $s p$ & 2.2 & 2.0 & 2.01 \\
\hline 3 & Bacillus $s p$ & 2.1 & 2.1 & 2.00 \\
\hline 4 & Pseudomonas $s p$ & 1.8 & 1.1 & 2.63 \\
\hline 5 & Bacillus $s p$ & 1.2 & 1.1 & 2.09 \\
\hline
\end{tabular}

Table 4. Optimization of Temperature on Phosphate solubilization

\begin{tabular}{|l|l|l|l|l|l|}
\hline Sl.no & Temperature $\left.\mathbf{~}^{\mathbf{0}} \mathbf{C}\right)$ & \multicolumn{4}{|l|}{ Phosphate solubilization(mg/l) } \\
\cline { 3 - 6 } & & PSB1 & PSB2 & PSB4 & PSB5 \\
\hline 1 & 27 & 0.25 & 0.23 & 0.24 & 0.22 \\
\hline 2 & 32 & 0.26 & 0.22 & 0.23 & 0.21 \\
\hline 3 & 37 & 0.24 & 0.23 & 0.22 & 0.23 \\
\hline 4 & 42 & 0.32 & 0.33 & 0.29 & 0.27 \\
\hline 5 & 47 & 0.29 & 0.30 & 0.27 & 0.26 \\
\hline
\end{tabular}

Table 5. Optimization of $\mathrm{pH}$ on Phosphate solubilization

\begin{tabular}{|l|l|l|l|l|l|}
\hline \multirow{2}{*}{ Sl.no } & \multirow{2}{*}{ PH Range } & \multicolumn{4}{|l|}{ Phosphate solubilization(mg/l) (mean of triplicate value) } \\
\cline { 2 - 6 } & & PSB1 & PSB2 & PSB4 & PSB5 \\
\hline 1 & 5.5 & 0.20 & 0.17 & 0.19 & 0.20 \\
\hline 2 & 6.5 & 0.22 & 0.24 & 0.22 & 0.19 \\
\hline 3 & 7.5 & 0.33 & 0.32 & 0.25 & 0.24 \\
\hline 4 & 8.5 & 0.32 & 0.30 & 0.25 & 0.23 \\
\hline 5 & 9.5 & 0.19 & 0.20 & 0.21 & 0.20 \\
\hline
\end{tabular}

Table 6. Phosphate Solubilizing Activities of 5 most $P$ solubilizing activity

\begin{tabular}{|l|l|c|c|}
\hline Sl.no & Isolates of PSB & $\begin{array}{l}\text { Soluble P concentration } \\
(\mathbf{m g} / \mathbf{l}) \text { in PVK media }\end{array}$ & $\begin{array}{l}\text { Soluble P concentration } \\
(\mathbf{m g} / \mathbf{l}) \text { in NBRIP media }\end{array}$ \\
\hline 1 & Azotobacter $\boldsymbol{s} p$ & $\mathbf{0 . 6 2 0}$ & $\mathbf{0 . 6 1 0}$ \\
\hline 2 & Rhizobium $\boldsymbol{s} \boldsymbol{p}$ & $\mathbf{0 . 6 9 0}$ & $\mathbf{0 . 7 0 0}$ \\
\hline 3 & Bacillus $\boldsymbol{s}$ p & $\mathbf{0 . 7 6 9}$ & $\mathbf{0 . 7 7 5}$ \\
\hline 4 & Pseudomonas $\boldsymbol{s p}$ & $\mathbf{0 . 8 7 5}$ & $\mathbf{0 . 8 9 0}$ \\
\hline 5 & Bacillus $\boldsymbol{s p}$ & $\mathbf{0 . 5 2 0}$ & $\mathbf{0 . 5 5 5}$ \\
\hline
\end{tabular}

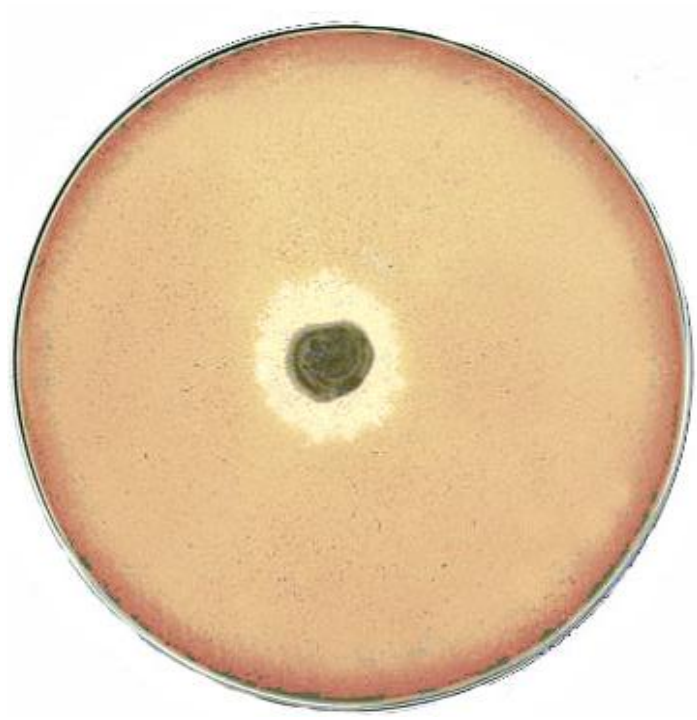

Photo.no.1

\section{Conclusions}

It was concluded from the present study that PSB exhibited a broad range of variations in soils collected from different areas. Pseudomonas $s p$ shown highest solubilizing capacity. More studies are 
Isolation, Screening and Characterization of Phosphate Solubilizing Bacteria from Karwar Costal Region.

warranted to identify and understand the significance and mechanism underlying the formation of soluble phosphate by PSB and its benefits as bio-inoculants.

\section{ACKNOWLEDGEMENT}

The authors are thankful to the Department of Biotechnology, Government arts and science college Karwar, for providing necessary facilities to carry out this study.

\section{REFERENCES}

[1] Wang X., Wang Y., Tian J., Lim BL., Yan X. and Liao H, Overexpressing AtPAP15 enhances phosphorus efficiency in soybean, Plant Physiol 151:233-240 (2009).

[2] Shenoy V.V and Kalagudi G.M, Enhancing plant phosphorus use efficiency for sustainable cropping, Biotechnol Adv 23:501-513 (2005).

[3] Ahemad M., Zaidi A., Khan M.S and Oves M, Biological importance of phosphorus and phosphate solubilizing microorganisms - an overview, In: Khan MS, Zaidi A (eds) Phosphate solubilizing microbes for crop improvement. Nova, New York, pp 1-4 (2009).

[4] Ahemad M., Khan M.S, Effect of fungicides on plant growth promoting activities of phosphate solubilizing Pseudomonas putida isolated from mustard (Brassica campestris) rhizosphere, Chemosphere 86:945-950 (2012).

[5] Khan M.S., Zaidi A., Wani P.A., Ahemad M and Oves M, Functional diversity among plant growth-promoting rhizobacteria, In: Khan MS, Zaidi A, Musarrat J (eds) Microbial strategies for crop improvement. Springer, Berlin, pp 105-132 (2009).

[6] Khan MS., Ahmad E., Zaidi A and Oves M, Functional aspect of phosphate-solubilizing bacteria: importance in crop production, In: Maheshwari DK et al (eds) Bacteria in agrobiology: crop productivity. Springer, Berlin, pp 237-265 (2013).

[7] Kannapiran. E and Sri Ramkumar V, Isolation of phosphate Solubilizing bacteria from sediments of Thondi coast, Palk Strait, Southeast coast of India. Annals of Biological Research.25:157-163. (2011)

[8] Brady N.C and R.R. Weil, Soil Phosphorus and Potassium, In: The Nature and Properties of Soils (13th Ed.). Upper Saddle River, NJ: Prentice-Hall, Inc. ( 2002).

[9] Vessey J. K, Plant growth promoting rhizobacteria as biofertilizers, Plant and Soil, 255, 571-586 (2003).

[10] Afzal A., M. Ashraf., A. Saeed., Asad and M. Farooq, Effect of phosphate solubilizing microorganisms on phosphorus uptake, yield and yield traits of wheat (Triticum aestivum L.) in rainfed area, International Journal of Agriculture and Biology, 7: 1560-8530 (2005).

[11] Sundara rao, W.V.B. and M.K. Sinha, Phosphate dissolving microorganism in the soil and rhizosphere. Indian Journal of Agricultural Science 33: 272-278 (1963).

[12] Pikovskaya, R.I, Mobilization of phosphorus in soil in connection with the vital activity of some microbial species. Mikrobiologiya 17, 362-370. (1948).

[13] Mc Fadden. Biochemical tests for identification of Medical bacteria. Williams and Wilkins, Baltimore, USA: 51-54 (1980).

[14] Edi-Premono, M.A. Moawad and P.L.G. Vleck, Effect of phosphate solubilizing Pseudomonas putida on the growth of maize and its survival in the rhizosphere. Indonesian Journal of Crop Sciences, 11: 13-23 (1996).

[15] Nautiyala, C.S., P. Bhadauria, Kumar, H. Lal and R. Mondal, Stress induced phosphate solubilization in bacteria isolated from alkaline soils. FEMS Microbiology Letters, 182: 291-296 (1999).

[16] Uma Maheswar ,N., and G. Sathiyavani, Solubilization of phosphate by Bacillus Sps, from groundnut rhizosphere Arachis hypogaea L. Journal of Chemical and Pharmaceutical Research. 48:4007- 401(2012).

[17] Md. Tofazzal Islama, Abhinandan Deoraa, Yasuyuki Hashidokoa, Atiqur Rahmana, Toshiaki Itoa, and Satoshi Taharaa, Isolation and Identification of

[18] Potential Phosphate Solubilizing Bacteria from the Rhizoplane of Oryza sativa L. cv. BR29 of Bangladesh. Z. Naturforsch. 62c, 103-110 (2007). 
[19] Amardip Singh., Poonam and Ghosh., A.K. Screening and Assessment of Phosphate Solubilising Microbes as Potential Biofertilizer, isolated from Ecosystem of Bihar. Asian Journal of Experimental Biological Science .32:397-406 (2012).

[20] Yahya, A. and K. Al-Azwais, Occurrence of phosphate solubilizing bacteria in some Iraqi soil. Plant and Soil, 117: 135-141(1989).

[21] Halder AK, Mishra AK, Chakarbarthy PK, Solubilization of inorganic phosphate by Bradyrhizobium. Ind. J. Exp. Biol. 29: 28-31(1991).

[22] Shruti Agrawal and R. K. Pathak, Phosphate Solubilization by Alcaligenes faecalis over Pseudomonas fluorescens. Agricultural Science Research Journals. 22: $92-94$ (2012.)

[23] Mehrvarz s and M.R.chaichi, Effect of Phosphate Solubilizing Microorganisms and Phosphorus Chemical Fertilizer on Forage and Grain Quality of Barely (Hordeum vulgare L.) AmericanEurasian J. Agric. \& Environ. Sci., 3 (6): 855-860, (2008). 